\title{
Korsakoff syndrome from retrochiasmatic suprasellar lesions: rapid reversal after relief of cerebral compression in 4 cases
}

\author{
Luis E. Savastano, MD, ${ }^{1}$ Todd C. Hollon, MD, ${ }^{1}$ Ariel L. Barkan, MD, ${ }^{1,2}$ and Stephen E. Sullivan, MD' \\ Departments of ${ }^{1}$ Neurosurgery and ${ }^{2}$ Internal Medicine, University of Michigan, Ann Arbor, Michigan
}

\begin{abstract}
Korsakoff syndrome is a chronic memory disorder caused by a severe deficiency of thiamine that is most commonly observed in alcoholics. However, some have proposed that focal structural lesions disrupting memory circuits-in particular, the mammillary bodies, the mammillothalamic tract, and the anterior thalamus-can give rise to this amnestic syndrome. Here, the authors present 4 patients with reversible Korsakoff syndromes caused by suprasellar retrochiasmatic lesions compressing the mammillary bodies and adjacent caudal hypothalamic structures.

Three of the patients were found to have large pituitary macroadenomas in their workup for memory deficiency and cognitive decline with minimal visual symptoms. These tumors extended superiorly into the suprasellar region in a retrochiasmatic position and caused significant mass effect in the bilateral mammillary bodies in the base of the brain. These 3 patients had complete and rapid resolution of amnestic problems shortly after initiation of treatment, consisting of resection in 1 case of nonfunctioning pituitary adenoma or cabergoline therapy in 2 cases of prolactinoma. The fourth patient presented with bizarre and hostile behavior along with significant memory deficits and was found to have a large cystic craniopharyngioma filling the third ventricle and compressing the midline diencephalic structures. This patient underwent cyst fenestration and tumor debulking, with a rapid improvement in his mental status. The rapid and dramatic memory improvement observed in all of these cases is probably due to a reduction in the pressure imposed by the lesions on structures contiguous to the third ventricle, rather than a direct destructive effect of the tumor, and highlights the essential role of the caudal diencephalic structures-mainly the mammillary bodies-in memory function.

In summary, large pituitary lesions with suprasellar retrochiasmatic extension and third ventricular craniopharyngiomas can cause severe Korsakoff-like amnestic syndromes, probably because of bilateral pressure on or damage to mammillary bodies, anterior thalamic nuclei, or their major connections. Neuropsychiatric symptoms may rapidly and completely reverse shortly after initiation of therapy via surgical decompression of tumors or pharmacological treatment of prolactinomas. Early identification of these lesions with timely treatment can lead to a favorable prognosis for this severe neuropsychiatric disorder.
\end{abstract}

https://thejns.org/doi/abs/10.3171/2017.1.JNS162719

KEY WORDS mammillary body compression; craniopharyngioma; Korsakoff-like amnestic syndrome; Korsakoff syndrome; pituitary macroadenoma; oncology; pituitary surgery

$\mathrm{K}$ ORSAKOFF syndrome is a neuropsychiatric disorder characterized by severe memory deficits generally disproportionate to any other impairment in cognitive function. ${ }^{9,23}$ Since the original description of this condition by Sergei Korsakoff in 1887, the syndrome has been associated with thiamine deficiency in the setting of chronic alcoholism or other disease related to severe malnutrition or malabsorption, such as prolonged intravenous feed- ing, cancer, or acquired immunodeficiency syndrome..$^{4,18}$ However, some have reported that focal structural lesions disrupting the circuit involving the mammillary bodies, the mammillothalamic tract, and the anterior thalamus can give rise to a severe amnestic syndrome., ${ }^{722}$ Here, we present 4 patients with reversible Korsakoff-like amnestic syndromes caused by suprasellar retrochiasmatic lesions compressing the mammillary bodies and adjacent caudal

ABBREVIATIONS IGF-1 = insulin-like growth factor 1.

SUBMITTED October 26, 2016. ACCEPTED January 5, 2017.

INCLUDE WHEN CITING Published online June 2, 2017; DOI: 10.3171/2017.1.JNS162719. 
hypothalamic structures. We also provide a review of similar cases in the literature and discuss the neuroanatomical and physiological bases for this fascinating syndrome.

\section{Case Reports}

\section{Case 1}

History and Examination

A 49-year-old man, previously healthy and without significant medical history, was referred to our clinic after a giant pituitary tumor was found in his workup for severe loss of short-term memory. In the 5 months before presentation, this successful businessman developed progressive cognitive decline and memory deficit to the point that his executive decisions were grossly diminished and his cognition was very slow and uncertain. His wife was particularly concerned about his memory and minimal content in conversation, in which he would repeat the same question several times during a single hour, which we also observed during his clinic visit. On examination, the patient was awake and oriented and in no acute distress. However, he had an extremely poor attention span and difficulty following complex commands. His neuroophthalmological examination showed normal eye movements with no evidence of ophthalmoplegia; however, his mental status was too poor to test visual fields by confrontation. Brain MRI disclosed the presence of a $5.3-\mathrm{cm}$ pituitary tumor with suprasellar extension and mass effect to caudal hypothalamic structures, mammillary bodies, and fornices (Fig. 1A-C). Lateral ventricles were mildly enlarged, with minimal transependymal flow. Laboratory results included a prolactin level of $8300 \mathrm{ng} / \mathrm{ml}$, which was diagnostic of a prolactinoma. His testosterone and bioavailable testosterone were low, but insulin-like growth factor 1 (IGF1), cortisol, and thyroid functions were intact.

\section{Treatment and Follow-Up}

The patient was started on cabergoline $0.5 \mathrm{mg}$ twice a week. Twelve hours after the first dose, his memory and cognition were remarkably improved. Within 3 weeks of cabergoline treatment, his prolactin lowered to $82 \mathrm{ng} / \mathrm{ml}$, and his cognitive abilities remained normal at the followup 6 months after presentation. Follow-up MRI performed 6 months later showed $>75 \%$ decrease in tumor size and interval resolution of mass effect to the structures forming the floor of the third ventricle, which was virtually free of any tumor involvement (Fig. 1D-F).

\section{Case 2}

\section{History and Examination}

A 37-year-old man without significant medical history was referred to our clinic with a 1-year history of severe, progressive cognitive dysfunction with associated visual dysfunction. The cognitive decline, apathy, and memory impairment were so severe that at the time of presentation he had lost his job, was unable to care for himself, and, when asked simple questions, would perseverate, repeating the same questions over and over for several minutes. Neurological examination was challenging given his profound attention deficit and difficulty in following com- mands, but he had a questionable subtle bitemporal hemianopia, worse on the right side. Brain MRI reveled a giant multilobulated sellar-suprasellar mass extending into the third ventricle, consistent with a cystic pituitary macroadenoma (Fig. 1G-I). The lesion extended superiorly and posteriorly with severe compression of the mammillary bodies, hypothalamus, lower fornices, and anterior thalamus and was heterogeneously enhancing with evidence of chronic bleeding and cyst formation. No signs or symptoms of hydrocephalus or increased intracranial pressure were identified on examination or radiology. Laboratory results included a prolactin level of $9100 \mathrm{ng} / \mathrm{ml}$, which was diagnostic of a prolactinoma.

\section{Treatment and Follow-Up}

The patient was started on cabergoline $0.5 \mathrm{mg}$ twice a week. Two days later, he had full restoration of memory and cognitive abilities. The patient was last seen at followup 1 year after diagnosis, and he continued to be neurologically and cognitively intact and living a healthy and productive life. Brain MRI performed 9 months after starting cabergoline showed virtually complete resolution of the giant pituitary tumor with 2 small, residual hemorrhagic cysts in the sella and in the suprasellar cistern associated with the right mammillary body (Fig. 1J-L).

\section{Case 3}

History and Examination

A 51-year-old man with a distant history of mild closed head injury from a motorcycle accident was referred to our clinic after a large pituitary tumor was discovered on brain MRI in the workup for progressive short-term memory deficits. Symptoms included significant impairment of executive function, apathy, and cognitive decline. Complete neurological examination was positive for severe short-term memory loss but negative for focal signs, neuroophthalmological problems, or manifestations of hormonal excess or deficiencies. A comprehensive pituitary hormonal panel including prolactin with hook effect, IGF-1, free T4, bioavailable testosterone, and morning cortisol was obtained and was within normal limits for the patient's age and sex. Brain MRI revealed a large enhancing lesion with solid and cystic components centered in the sella turcica and extending superiorly and posteriorly, with mass effect and compression of the floor of the third ventricle (Fig. 2A-C). Overall, this was consistent with a large pituitary macroadenoma with suprasellar and retrochiasmatic extension compressing caudal diencephalic structures, mainly the mammillary bodies and the caudal hypothalamus. Otherwise, MRI was unremarkable with no evidence of hydrocephalus.

\section{Treatment and Follow-Up}

The patient underwent surgery via an expanded endonasal approach for resection of the pituitary tumor. Surgery was uneventful. Postoperative MRI showed grosstotal resection of the lesion with good decompression of the suprasellar structures (Fig. 2D-F). Pathology was consistent with a nonfunctioning pituitary adenoma. The day after surgery, the patient had dramatic improvement in his 
CASE 1 (PROLACTINOMA)

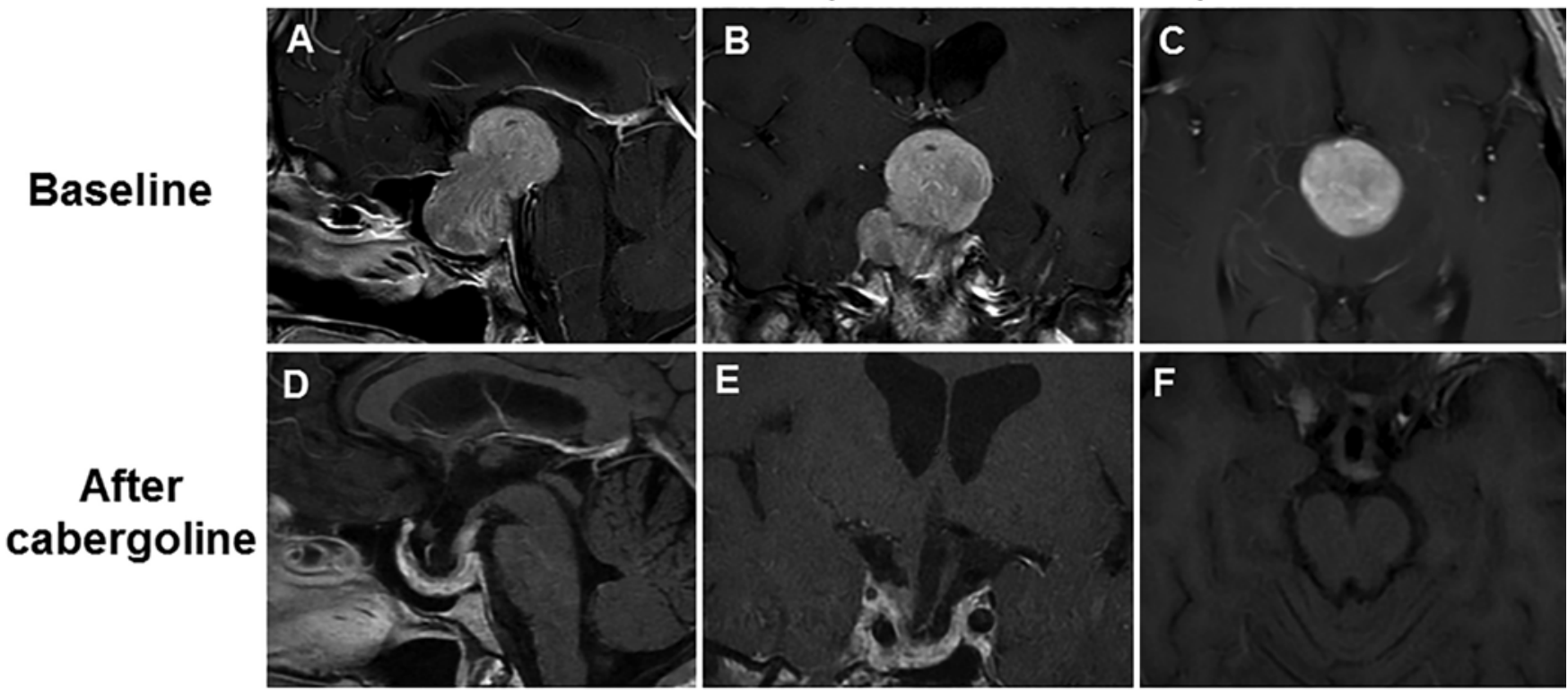

CASE 2 (PROLACTINOMA)
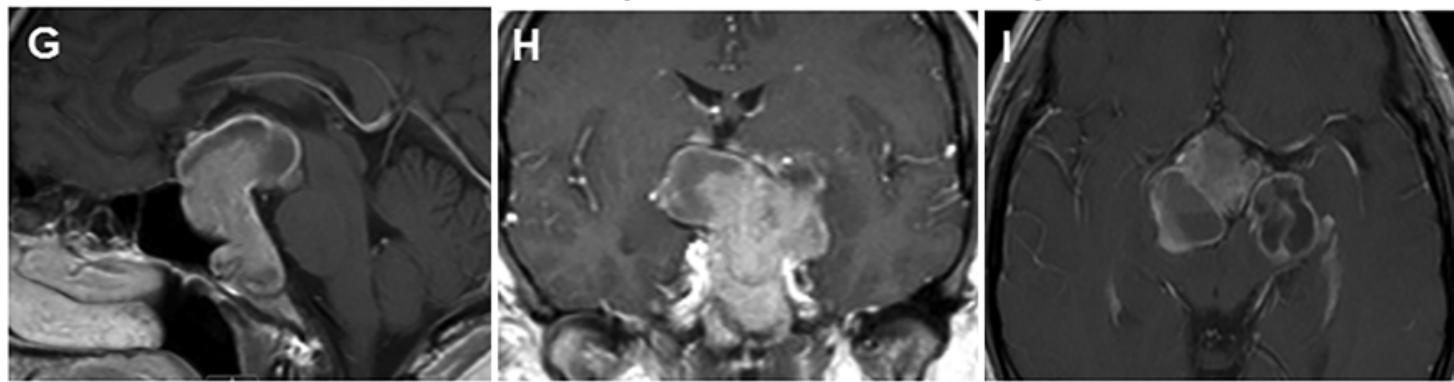

Baseline

After cabergoline
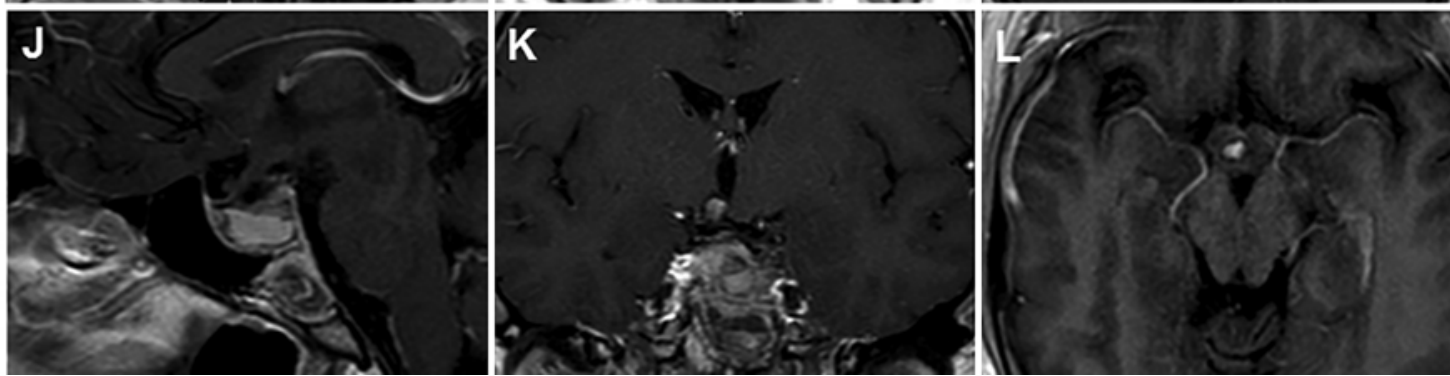

FIG. 1. Case 1. Sagittal (A), coronal (B), and axial (C) Gd-enhanced MR images obtained the time of diagnosis, showing a large enhancing sellar-suprasellar lesion causing mass effect on basal diencephalic structures. Gadolinium-enhanced MR images (D-F) obtained at the last follow-up appointment after initiation of cabergoline therapy, showing $>75 \%$ decrease in tumor size and interval resolution of mass effect to the structures forming the floor of the third ventricle. Case 2. Gadolinium-enhanced MR images (G-I) obtained at the time of diagnosis, showing giant multilobulated sellar-suprasellar mass extending into the third ventricle, consistent with a cystic pituitary macroadenoma, causing severe compression of the mammillary bodies, hypothalamus, lower fornices, and anterior thalamus. Gadolinium-enhanced MR images (J-L) obtained at the last follow-up appointment after initiation of cabergoline therapy, showing virtually complete resolution of the giant pituitary tumor with 2 small, residual hemorrhagic cysts in the sella and in the suprasellar cistern associated with the right mammillary body.

memory with the resolution of all cognitive deficits. He was last seen for follow-up 9 months after surgery and had normal hormonal and cognitive function.

\section{Case 4}

History and Examination

A 23-year-old man with no significant medical history presented to the emergency department with a 6-month history of increased headaches, decreased appetite, disinhibited behavior, and memory problems. The family reported that his short-term memory deficits were more prominent than other cognitive disorders. He had recently lost his full-time job due to increasing confusion, belligerence, memory deficits, and disinhibited behavior. On examination, he was hemodynamically stable and in no acute 


\section{CASE 3 (NONFUNCTIONING PITUITARY ADENOMA)}
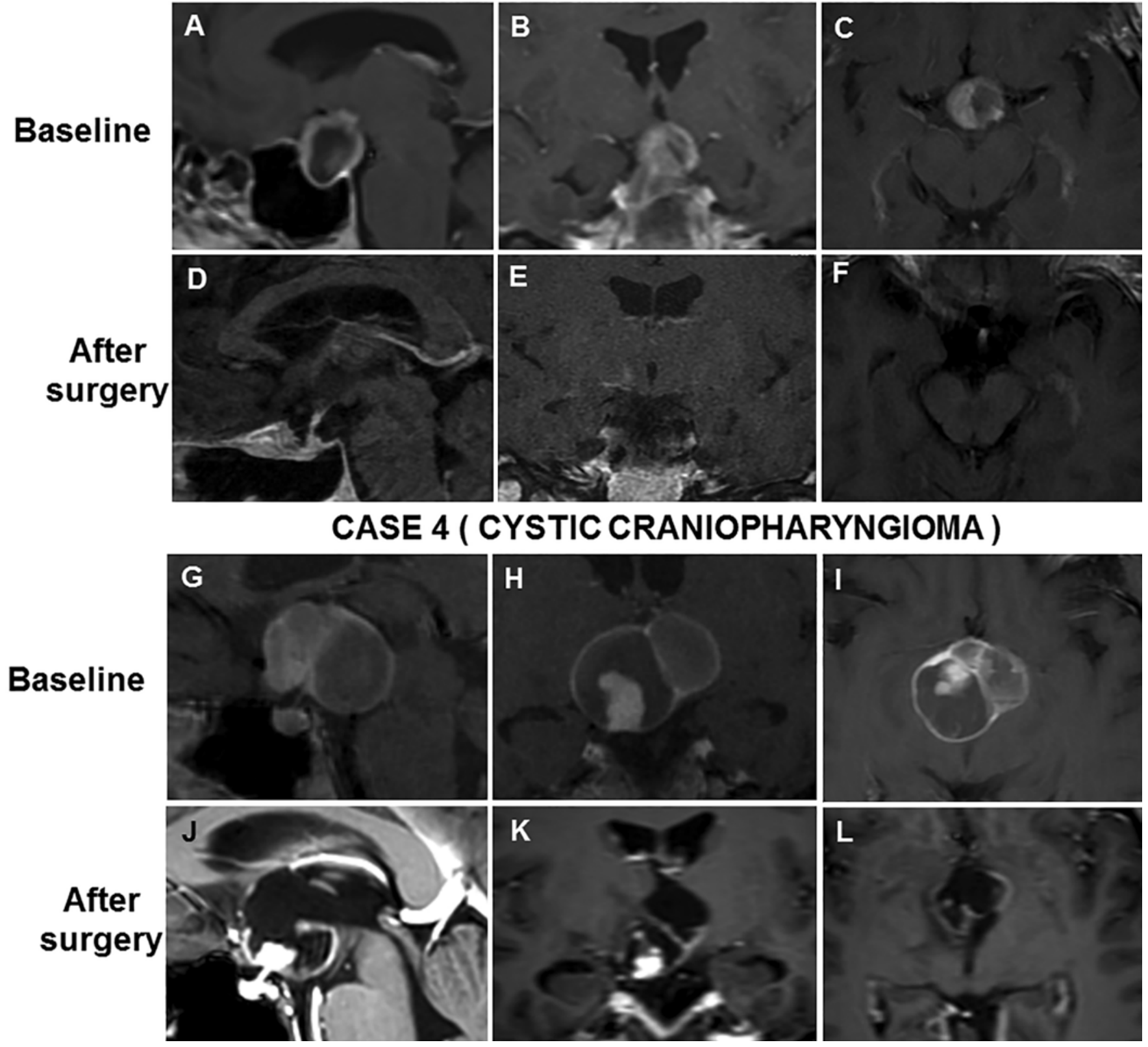

FIG. 2. Case 3. Sagittal (A), coronal (B), and axial (C) Gd-enhanced MR images obtained at the time of diagnosis, showing a large enhancing lesion with solid and cystic components centered in the sella turcica and extending superiorly and posteriorly, with mass effect and compression of the floor of the third ventricle. Gadolinium-enhanced MR images (D-F) obtained at the last follow-up appointment after surgical treatment, showing gross-total resection of the lesion with good decompression of the suprasellar structures. Case 4. Gadolinium-enhanced MR images (G-I) obtained at diagnosis, showing large, multiloculated, predominantly cystic mass with enhancing nodules in the sellar-suprasellar region with associated mass effect upon the optic chiasm and midbrain. Gadolinium-enhanced MR images (J-L) obtained at the last follow-up appointment after surgical treatment, showing debulking of the tumor with drainage of the cystic components resulting in decompression of the optic apparatus and hypothalamic structures.

distress. He was oriented to self but was unable to appropriately answer to place and time, even when provided with clues. He had poor attention, bizarre behavior, and poor short-term memory. Examination of cranial nerves was unremarkable. A formal neuroophthalmological evaluation demonstrated full confrontation visual fields, no afferent pupillary defect, and no papilledema. Brain MRI revealed a large, multiloculated, predominantly cystic mass with enhancing nodules in the sellar-suprasellar region, with associated mass effect upon the optic chiasm and midbrain (Fig. 2G-I). Overall, imaging findings were consistent with a craniopharyngioma.

\section{Treatment and Follow-Up}

He was started on hydrocortisone replacement therapy, and subsequent laboratory results showed low levels 
of free $\mathrm{T} 4$ at $0.75 \mathrm{ng} / \mathrm{dl}$, minimal elevation of prolactin at $33 \mathrm{ng} / \mathrm{ml}$, and normal IGF-1 at $350 \mathrm{ng} / \mathrm{ml}$. His total testosterone was very low at $21 \mathrm{ng} / \mathrm{dl}$, with decreased bioavailable testosterone at $4.6 \mathrm{ng} / \mathrm{dl}$. He underwent urgent ventriculoscopic debulking of the cystic component of the tumor, which achieved good decompression of the optic apparatus and hypothalamic structures per postoperative MRI (Fig. 2J-L). Pathology confirmed craniopharyngioma, WHO Grade I. The next day, the patient had normal memory and full resolution of cognitive and behavioral impairments. To reduce the risk of tumor progression, adjuvant radiation therapy was given in 31 treatments to a total dose of $55.8 \mathrm{~Gy}$. At the last follow-up 3 months after surgery, the patient continued to do very well neurologically and psychologically, with the ongoing need of hormone replacement.

\section{Discussion}

Korsakoff syndrome is a well-known neuropsychiatric disorder clinically diagnosed via identification of severe amnestic deficits, sometimes accompanied by confabulation and disorientation, in patients with a history of alcoholism or severe malnutrition. ${ }^{9}$ This syndrome was first described more than 130 years ago by Sergei Korsakoff, a Russian psychiatrist, who described in his doctoral dissertation a series of malnourished alcoholic patients with a particular amnestic syndrome disproportionate to other cognitive functions in the domain of language, problem solving, or executive functions. Historically, in both alcoholic and nonalcoholic populations, this syndrome has been primarily associated with thiamine deficiency, which leads to enzymatic malfunction and decreased levels of intracellular energy and an accumulation of glutamate with subsequent cellular toxicity and death. ${ }^{12}$ Nonetheless, it has been recognized that focal bilateral lesions in crucial structures of cognitive and memory circuits can give rise to severe amnestic disorders mimicking Korsakoff syndrome. ${ }^{7}$ To date, only a few cases of Korsakoff-like syndrome have been associated with rare structural lesions in the basal brain, including traumatic penetrating lesions, 5,20 neurovascular insults, $, 3,16,25$ and tumors such as craniopharyngiomas, ${ }^{11,25}$ third ventricular lymphomas, ${ }^{21}$ and cysts of the septum pellucidum. ${ }^{15}$ In addition, the onset of this syndrome has been reported following the removal of tumors of the third ventricle in both adult and pediatric populations $s^{1,2,7,8}$ and in the microsurgical treatment of anterior communicating artery aneurysms. ${ }^{13,19}$

Nonmetabolic or structural lesions causing Korsakoff syndrome were recently reviewed and analyzed in detail by Kril and Harper. ${ }^{10}$ In their paper, these authors reviewed the literature and correlated the neuropsychiatric findings with the anatomical and physiological circuits likely disrupted in each lesion. They concluded that the development of amnestic syndromes due to focal structural lesions requires bilateral damage of the thalamus or hypothalamus-in particular, the anterior thalamic nucleus and the medial mammillary nucleus of the hypothalamus-or injury to their major pathways, namely the fornix and mammillothalamic tract. Here, we present 4 patients with Korsakoff-like amnestic syndromes related to supra- sellar retrochiasmatic lesions. Although these patients had neuropsychiatric disturbances involving different cognitive domains, the medical team, which included a neurologist, felt that memory impairment was the outstanding mental defect. These patients were found to have large tumors involving the floor and/or sides of the third ventricle, likely disrupting cognitive and memory circuitry by direct damage of key nuclei or their major connections.

Craniopharyngiomas, which are neoplasms that develop from nests of epithelium derived from Rathke's pouch and are typically centered in the suprasellar/diencephalic regions, have been associated with Korsakoff-like amnestic syndromes., ${ }^{711,24}$ The patients presented in the cited series were found to have large lesions with mass effect on the floor and sides of the third ventricle during their workup for amnestic disorders, generally refractory to the relief of raised intracranial pressure. ${ }^{17,24}$ In a similar fashion, in our patient with craniopharyngioma, the mental symptoms rapidly cleared up upon cyst aspiration, fenestration, and/or lesion debulking. ${ }^{6}$ This suggests a causeeffect relationship between focal dysfunction of caudal and medial diencephalic structures with memory deficits, independent of increased intracranial pressure and mainly driven by direct mass effect and compression.

Although certain subtypes of pituitary tumors causing hormonal imbalances are known to be associated with neuropsychological abnormalities, such as in the case of Cushing's disease,${ }^{14}$ to our knowledge this is the first case series reporting Korsakoff syndrome caused by direct mass effect of pituitary lesions (prolactinoma, nonfunctioning adenoma, and craniopharyngioma) with suprasellar extension. As suggested by Kahn and Crosby in 1972, the development of a florid Korsakoff syndrome depends on bilateral lesions in one of the areas involved in the limbic and memory circuitry. ${ }^{7}$ Proximity of the 2 mammillary bodies in the base of the brain favors involvement of both nuclear masses and a major efferent to the thalami by midline tumors ascending through the suprasellar region, such us pituitary macroadenomas, or extending posteriorly from the third ventricle, such as a third ventricular craniopharyngioma, as discussed above. Interestingly, none of our patients with giant pituitary macroadenomas had significant visual dysfunction, suggesting that these tumors extended posteriorly into the suprasellar space in a retrochiasmatic position. The absence of visual manifestations probably translated into delayed presentation until tumors had reached a large size, causing significant compression of basal diencephalic structures. Although comprehensive cognitive testing was not performed, which is a limitation of our study, the 3 patients with pituitary macroadenomas had complete and rapid resolution of amnestic problems shortly after initiation of treatment, consisting of resection in 1 case of nonfunctioning pituitary adenoma or cabergoline therapy in 2 cases of prolactinoma. Both patients with giant prolactinomas had rapid resolution of severe amnestic, cognitive, and behavioral abnormalities shortly after initiation of cabergoline, suggesting that urgent resection is probably not needed to improve the prognosis of this subset of reversible Korsakoff syndromes. The rapid and dramatic memory improvement observed in all the cases presented here is probably due to a reduction in the pres- 
sure imposed by the lesions on structures contiguous to the third ventricle, rather than a direct destructive effect of the tumor, and highlights the essential role of the caudal diencephalic structures, mainly the mammillary bodies, in memory function.

\section{Conclusions}

Large pituitary lesions with suprasellar retrochiasmatic extension and third ventricular craniopharyngiomas can cause severe Korsakoff-like amnestic syndromes, probably as a result of bilateral pressure on, or damage to, mammillary bodies, anterior thalamic nuclei, or their major connections. Neuropsychiatric symptoms may rapidly and completely reverse shortly after initiation of therapy via surgical decompression of tumors or pharmacological treatment of prolactinomas. Early identification of these lesions with timely treatment can lead to a favorable prognosis for this severe neuropsychiatric disorder.

\section{References}

1. Carpentieri SC, Waber DP, Scott RM, Goumnerova LC, Kieran MW, Cohen LE, et al: Memory deficits among children with craniopharyngiomas. Neurosurgery 49:1053-1058, 2001

2. Cavazzuti V, Fischer EG, Welch K, Belli JA, Winston KR: Neurological and psychophysiological sequelae following different treatments of craniopharyngioma in children. J Neurosurg 59:409-417, 1983

3. Cole M, Winkelman MD, Morris JC, Simon JE, Boyd TA: Thalamic amnesia: Korsakoff syndrome due to left thalamic infarction. J Neurol Sci 110:62-67, 1992

4. Delay J, Brion S: Le Syndrome de Korsakoff. Paris: Masson, 1969

5. Dusoir H, Kapur N, Byrnes DP, McKinstry S, Hoare RD: The role of diencephalic pathology in human memory disorder. Evidence from a penetrating paranasal brain injury. Brain 113:1695-1706, 1990

6. Ignelzi RJ, Squire LR: Recovery from anterograde and retrograde amnesia after percutaneous drainage of a cystic craniopharyngioma. J Neurol Neurosurg Psychiatry 39:1231-1235, 1976

7. Kahn EA, Crosby EC: Korsakoff's syndrome associated with surgical lesions involving the mammillary bodies. Neurology 22:117-125, 1972

8. Konovalov AN, Dobrokhotova TA, Voronina IA, Urakov SV: [Case of Korsakoff syndrome and colloid cyst of the 3rd ventricle.] Zh Nevrol Psikhiatr Im S S Korsakova 98:49-51, 1998 (Russian)

9. Kopelman MD: The Korsakoff syndrome. Br J Psychiatry 166:154-173, 1995

10. Kril JJ, Harper CG: Neuroanatomy and neuropathology associated with Korsakoff's syndrome. Neuropsychol Rev 22:72-80, 2012

11. Kupers RC, Fortin A, Astrup J, Gjedde A, Ptito M: Recovery of anterograde amnesia in a case of craniopharyngioma. Arch Neurol 61:1948-1952, 2004

12. Langlais PJ: Pathogenesis of diencephalic lesions in an exper- imental model of Wernicke's encephalopathy. Metab Brain Dis 10:31-44, 1995

13. Lindqvist G, Norlén G: Korsakoff's syndrome after operation on ruptured aneurysm of the anterior communicating artery. Acta Psychiatr Scand 42:24-34, 1966

14. Mauri M, Sinforiani E, Bono G, Vignati F, Berselli ME, Attanasio R, et al: Memory impairment in Cushing's disease. Acta Neurol Scand 87:52-55, 1993

15. Neciga EG, Peralta AG, Polaina M, Sureda B, Bautista J: Cyst of the septum pellucidum and Korsakoff's psychosis. Eur Neurol 29:99-101, 1989

16. Renou P, Ducreux D, Batouche F, Denier C: Pure and acute Korsakoff syndrome due to a bilateral anterior fornix infarction: a diffusion tensor tractography study. Arch Neurol 65:1252-1253, 2008

17. Russell RW, Pennybacker JB: Craniopharyngioma in the elderly. J Neurol Neurosurg Psychiatry 24:1-13, 1961

18. Scalzo SJ, Bowden SC, Ambrose ML, Whelan G, Cook MJ: Wernicke-Korsakoff syndrome not related to alcohol use: a systematic review. J Neurol Neurosurg Psychiatry 86:1362-1368, 2015

19. Taren JA: Anatomical pathways related to the clinical findings in aneurysms of the anterior communicating artery. $\mathbf{J}$ Neurol Neurosurg Psychiatry 28:228-234, 1965

20. Teuber HL, Milner B, Vaughan HG Jr: Persistent anterograde amnesia after stab wound of the basal brain. Neuropsychologia 6:267-282, 1968

21. Toth C, Voll C, Macaulay R: Primary CNS lymphoma as a cause of Korsakoff syndrome. Surg Neurol 57:41-45, 2002

22. Vann SD, Aggleton JP: The mammillary bodies: two memory systems in one? Nat Rev Neurosci 5:35-44, 2004

23. Victor M, Adams RD, Collins GH: The Wernicke-Korsakoff Syndrome and Related Disorders due to Alcoholism and Malnutrition, ed 2. Philadelphia: Davis, 1989

24. Williams M, Pennybacker J: Memory disturbances in third ventricle tumours. J Neurol Neurosurg Psychiatry 17:115123,1954

25. Yoneoka Y, Takeda N, Inoue A, Ibuchi Y, Kumagai T, Sugai T, et al: Acute Korsakoff syndrome following mammillothalamic tract infarction. AJNR Am J Neuroradiol 25:964968,2004

\section{Disclosures}

The authors report no conflict if interest concerning the materials or methods used in this study or the findings specified in this paper.

\section{Author Contributions}

Conception and design: Sullivan, Savastano. Acquisition of data: all authors. Analysis and interpretation of data: all authors. Drafting the article: Savastano. Critically revising the article: Savastano. Reviewed submitted version of manuscript: all authors. Approved the final version of the manuscript on behalf of all authors: Sullivan. Study supervision: Sullivan, Barkan.

\section{Correspondence}

Stephen E. Sullivan, Department of Neurosurgery, University of Michigan, 1500 E Medical Center Dr., Rm. 3552, Ann Arbor, MI 48109-5338. email: ssulliva@med.umich.edu. 